\title{
Giant sacral tarlov cyst and renal insufficiency
}

\begin{abstract}
Perineural sacral cysts, also called Tarlov cysts, are pathologic collections of cerebrospinal fluid (CSF). They are typically located at the junction of the dorsal ganglion and the posterior nerve root and use to develop between the endoneurium and perineurium of the nerve root. ${ }^{1}$ Tarlov cysts were described in 1938 as an incidental finding during an autopsy in fillum terminale. ${ }^{2}$

They occur around 1\% of the general population and generally are most commonly small, asymptomatic and discovered as an incidental finding on lumbosacral imaging studies obtained for evaluation of degenerative spine disease. However, in a symptomatic population the prevalence was reported at $4.6 \%$. They are more comom at female patients. ${ }^{3,4}$ The most common location in the spine is the sacral region, with the $\mathrm{S} 2 / \mathrm{S} 3$ nerve roots most commonly affected. ${ }^{5}$

The patient may complain low back pain, sciatica, coccydinia or cauda equina syndrome. The cysts are usually diagnosed on Magnetic Ressonance Image (MRI), which shows the lesion arising from sacral nerve roots. ${ }^{6}$ Ten years after his original description, Tarlov advised extensive surgery with sacral laminectomy and excision of the cyst along with the nerve root. ${ }^{7}$ Paulsen reported CT-guided percutaneous aspiration of Tarlov cysts for relief of sciatica. ${ }^{3}$ Recently, microsurgical excision of the cyst has been described, ${ }^{1}$ as well as clipping technique. ${ }^{8}$ Also, closure of the communication between arachnoid and cyst, sacrificing near neural roots, has been reported. ${ }^{9}$
\end{abstract}

Volume 5 Issue 5 - 2018

\author{
Vagner Clayton de Paiva, Guilherme Augusto \\ Foizer, luri Tomaz de Vasconcelos, Alberto \\ Cliquet Junior, Carlos Górios \\ UNICAMP, Brazil
}

\begin{abstract}
Correspondence: Vagner Clayton de Paiva, UNICAMP,Abilio Soares St. 509/72, ZIP 02004-005, Brazil,Tel +55 II 973933205 Email vagnerdepaiva@yahoo.com.br ORCID 0000-0002-7843-236X
\end{abstract}

Received: July 31, 2018 | Published: September 18, 2018

\section{Case report}

A 45-year-old female patient presented with intense low back pain for 2 years, irradiating for both lower limbs and perineum with significant worsening in the orthostatic position. She referred weakness of lower limbs and bladder dysfunction with urinary retention. She developed renal insufficiency with increase of urea nitrogen $(73 \mathrm{mg} / \mathrm{dl})$ and creatinine $(2.5 \mathrm{mg} / \mathrm{dl})$. Patient had controlled high blood pressure, without other comorbidities.

\section{Physical exam}

Patient needed crutches to walk. She presented with hypoesthesia in the plantar region of left foot and degree IV force for plantar flexion of both feet. Anal sphincter reflex was reduced and she had recurrent urinary retention, with intermittent urinary catheterization. No signs of myelopathy or pyramidal release were found.

Electroneuromyography: chronic axonal loss of low sacral roots.

Computed tomography: Significant bone destruction of posterior elements of S1 and S2 (Figure 1).

A.
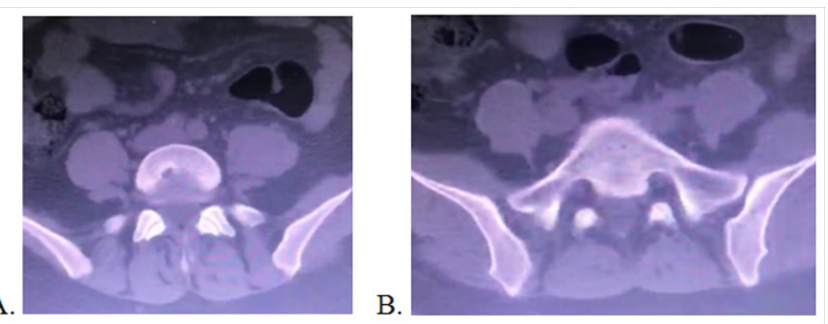

Figure I CT showed important destruction of posterior elements of: A. SI and B.S2.
Magnetic Resonance Imaging (MRI) showed a perineural cyst extending from S2 to S4, remodeling posterior walls of S2 and S4 and enlarging sacral foramina of S2 to the right and S3 to the left, occupying almost entire vertebral canal (Figure 2).
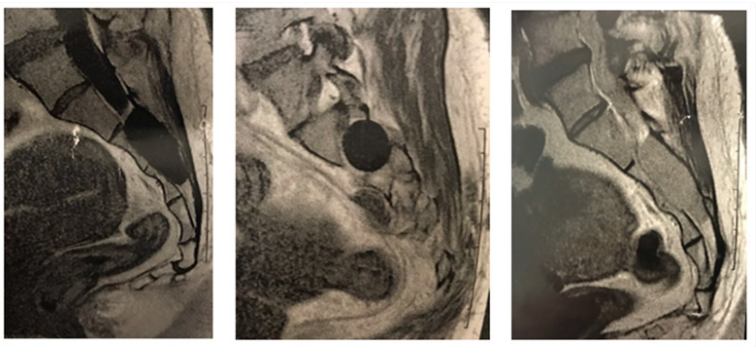

Figure $2 \mathrm{MRI}$ of sacral spine: giant epidural cist, from S2 to S4.

S1 and S2 bilateral foraminal blockage were performed, with significant improvement of pain for 1 week, which then returned.

New MRI, gadolinium enhanced, showed an intramedullary constriction band, at the level of vertebrae S1-S2, with severe stenosis (Figure 3).

We performed wide S2 and S3 laminectomy and foraminotomy and cyst excision. Liquor leakage followed cist incision and nerve fibers were found inside the cyst. We proceeded then raffia of duramater by 6.0 Nyon suture, fibrin glue and muscular plasterer.

Patient presented intense headache post-operatively and, to overcome the CSF leak postoperatively, we used the protocol described by Naves, with seven days with patient at zero degree recumbence. ${ }^{10}$ Even so, two weeks after surgery she developed clinical evident liquor leakage, treated successfully by cutaneous excision and skin suture. Since that, she did not have any other complication. 

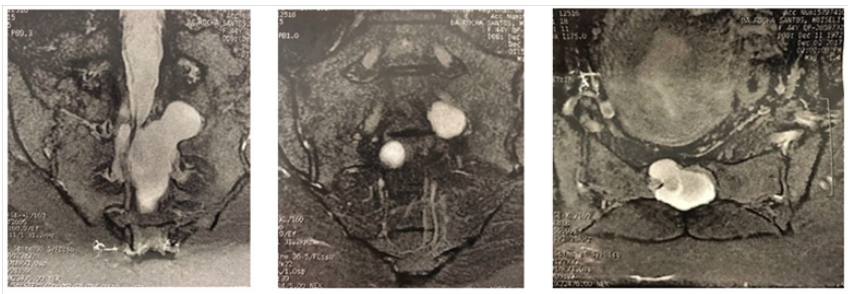

Figure 3 Gadolinium enhanced MRI shows important constriction band with canal stenosis in SI-S2.

Histopathological study accused fibroconjunctive tissue without any atypia. Pre and intraoperative findings were compatible with diagnosis of Tarlov's cyst. Two weeks after last surgery, she had normal bladder and intestinal control and at 6 weeks patient was asymptomatic for low back pain and lower limbs pain, with degree $\mathrm{V}$ force for all lower limbs muscular groups, with patient walking by herself, without any external support.

Renal function recovered after 6 weeks of surgery, with urea at 44 $\mathrm{mg} / \mathrm{dl}$ and creatinine: $1.6 \mathrm{mg} / \mathrm{dl}$.

\section{Discussion}

Tarlov cysts occur at the transition of the dorsal root ganglion and the posterior nerve root, between the endoneurium and perineurium. Cause of sacral perineural cyst remains unclear. Tarlov postulated that it is caused by local trauma, with hemorrhage into subarachnoid space caused accumulations of red cells, which impeded the venous drainage in perineurium and epineurium, leading to rupture with subsequent cyst formation. Four out of the seven patients in Tarlov's article had a history of trauma. ${ }^{11}$ Schreiber et al. also supported a traumatic cause of cyst formation. ${ }^{12}$ Although, many patients with perineural cyst do not have histories of trauma, so some authors believe that perineural cysts are congenital, with a arachnoidal proliferations along the exiting sacral root sleeve. ${ }^{13}$

Due to cerebrospinal fluid inflow, Tarlov's cyst can grow, compressing or stretching adjacent nerve roots. Pain is the most frequent symptom, in form of persistent back pain or sciatic pain exacerbated by standing, walking, and coughing. Symptoms tend to relieve by lying down. Furthermore, these cysts may cause also motor deficits and bladder/bowel dysfunction. ${ }^{14-16}$ Our patient presented all the clinical signals described above.

In physiological conditions, the bladder's parasympathetic efferent nerve (pelvic nerve, formed by S2 to S4) contracts the detrusor muscle, while sympathetic efferent nerve (T11 to L2) relaxes detrusor muscle. Pudendal nerve (somatic efferent commands, S1 to S4) innervates the external urethral sphincter. ${ }^{17}$

At filum terminale dysfunction, parasympathetic stimulation is absent, which leads to detrusor weakness that culminates as a neurogenic bladder.$^{18}$ Concomitantly, dysfunction of S1 to S4 leads to external urethral sphincter dysfunction. ${ }^{17}$ Chronic neurogenic bladder creates a reverse flow of urine to kidney and, at advanced cases, kidney failure. ${ }^{19}$

Smith et al., ${ }^{20}$ described diferents types of sacral tumors that can lead to neurogenic bladder, including hemangioma, giant lipomas and Tarlov's cyst. At this patient specifically prompt decompression led her to complete recovery of vesical control and partial recovery of kidney function. Considering Cockcroft gault formula, she had a creatinine clearance of $38.6 \mathrm{~mL} / \mathrm{min}$ pre operatively and passed to $60,2 \mathrm{~mL} / \mathrm{min}$ at 6 weeks post operatively. ${ }^{21}$ It means that she left grade III chronic renal insufficiency (CRI) to grade II CRI with normalization of urea and creatinine blood levels. ${ }^{22}$

\section{Conclusion}

This relate of case corroborates the importance of early decompression of sacral tumors in patients that present with neurogenic bladder dysfunction and consequent renal dysfunction. Early neural decompression can change positively the natural history of the patient, with improvement of the renal function and consequent improvement in the quality of life.

\section{Acknowledgements}

None.

\section{Conflict of interest}

The author declares that there is no conflict of interest.

\section{References}

1. Guo D, Shu K, Chen R, et al. Microsurgical treatment of symptomatic sacral perineurial cysts. Neurosurgery. 2007;60(6):1059-1066.

2. Tarlov IM. Perineural cysts of the spinal nerve roots. Arch Neural Psychiatry. 1938;40:1067-1074

3. Paulsen RD, Call GA, Murtagh FR. Prevalence and percutaneous drainage of cysts of the sacral nerve root sheath (Tarlov cysts). AJNR Am J Neuroradiol. 1994;15(2):293-299.

4. Caspar W, Papavero L, Nabhan A, et al. Microsurgical excision of symptomatic sacral perineurial cysts: A study of 15 cases. Surg Neurol. 2003;59(2):101-106.

5. Seaman WB, Furlow LT. The myelographic appearance of sacral cysts. $J$ Neurosurg. 1956;13:88-94

6. Rodziewicz GS, Kaufman B, Spetzler RF. Diagnosis of sacral perineural cysts by nuclear magnetic resonance. Surg Neurol. 1984;22(1):50-52.

7. Tarlov IM. Cysts (perineurial) of the sacral roots. $J \mathrm{Am} \mathrm{Med}$ Assoc. 1948;138(10):740-744.

8. Cantore G, Bistazzoni S, Esposito V, et al. Sacral Tarlov cyst: surgical treatment by clipping. World Neurosurg. 2013;79(2):381-389.

9. Kurz LT, Centeno RS, Alksne JF. Perineural cysts of the sacral nerve roots. Neuro-Orthop. 1989;7:24-31.

10. Naves CD, Silva LE, Castro CJ, Pereira MG, Teixeira RJ. Lumbar scoliosis caused by dural ectasia. Int J Radiol Radiat Ther. 2018;5(3):172-174.

11. Tarlov IM. Spinal perineural and meningeal cysts. J Neural Neurosurg Psychiatry. 1970;33(6):833-843.

12. Schreiber F, Haddad B. Lumbar and sacral cysts causing pain. $J$ Neurosurg. 1951; 8:504-509.

13. Fortuna A, La Torre E, Ciappetta P. Arachnoid diverticula: a unitary approach to spinal cysts communicating with the subarachnoid space. ActaNeurochir. 1977;39(3-4):259-268.

14. Elsawaf A, Awad TE, Fesal SS. Surgical excision of symptomatic sacral perineurial Tarlov cyst: case series and review of the literature. Eur Spine J. 2016;25(11):3385-3392.

15. Lucantoni C, Than $\mathrm{KD}$, Wang AC, et al. Tarlov cysts: a controversial lesion of the sacral spine. Neurosurg Focus. 2011;31(6):e14.

16. Slipman CW, Bhat AL, Bhagia SM, et al. Abdominal pain secondary to a sacral perineural cyst. Spine J. 2003;3(4):317-320. 
17. Benevento BT, Sipski ML. Neurogenic Bladder, Neurogenic Bowel, and Sexual Dysfunction in People With Spinal Cord Injury. Phys Ther. 2002;82(6):601-612.

18. Wolters JP, Hellstrom WJ. Current concepts in ejaculatory dysfunction. Rev Urol. 2006;8(4):S18-S25.

19. Cho PS, Bauer SB, Pennison M, et al. Sacral agenesis and neurogenic bladder: long-term outcomes of bladder and kidney function. $J$ Pediatr Urol. 2016;12(3):158.
20. Smith ZA, Li Z, Raphael D, et al. Sacral laminoplasty and cystic fenestration in the treatment of symptomatic sacral perineural (Tarlov) cysts: Technical case report. Surg Neurol Int. 2011;2:129.

21. Cockcroft DW, Gault MH. Prediction of creatinine clearance from serum creatinine. Nephron. 1976;16(1):31-41.

22. Levin A, Stevens PE, Bilous RW, et al. KDIGO 2012 clinical practice guideline for the evaluation and management of chronic kidney disease. Kidney Int. 2013;3:1-150. 